\title{
O Brasil de Ulrich Becher no Romanceiro Brasileiro: a harmonia em questão
}

\author{
Ruth Bohunovsky ${ }^{1}$
}

\begin{abstract}
Brazil - a country of the future (Brasilien - ein Land der Zukunft), written by Stefan Zweig in the 40s, is one of the few books to portray Brazil as a harmonious country. However, although the book is widely acknowledged as a fine piece of work, one cannot afford to ignore that some other German authors from the same period presented other entirely different views of Brazil. This paper focuses on the novel Romanceiro Brasileiro by Ulrich Becher, an author relatively neglected in the Germanic studies. The primary aim is to examine some aspects of the image of Brazil. Unlike Zweig, who shows a tendency to conceal potential conflicts which could threaten his idea of a harmonious Brazil, Becher points out the contradictions and disparities of the country, focusing on aspects which contradict the idyllic image suggested by Zweig, such as Brazil's serious social problems and injustice. By doing so, Becher may have created a more plausible image of Brazil.
\end{abstract}

Keywords: Ulrich Becher, Stefan Zweig, the image of Brazil in German literature.

Resumo: Poucas obras marcaram tanto o imaginário acerca do Brasil como o livro de Stefan Zweig intitulado Brasil - um país do futuro, escrito nos anos 1940. No entanto, não obstante a fama desse livro e de sua visão de um Brasil harmonioso, não se deve esquecer que existem livros de outros autores de língua alemã, escritos nessa mesma época, com visões e interpretações acerca do Brasil divergentes daquelas reveladas por Zweig. Neste artigo, são abordados alguns aspectos da imagem do Brasil presentes no Romanceiro Brasileiro, de Ulrich Becher - um autor relativamente negligenciado pelos estudos germânicos. Zweig, na procura por benesses do governo de Getúlio Vargas, demonstra uma tendência de ocultar possíveis conflitos que poderiam ameaçar a harmonia que ele acredita ter encontrado no Brasil. Ao contrário disso, Becher - para quem esse país foi apenas um lugar de passagem - destaca justamente as contradições e dissonâncias presentes, focalizando aspectos conflitantes com uma imagem idílica, como os grandes problemas e injustiças sociais, e chega, assim, a elaborar uma imagem talvez mais plausível do Brasil.

Palavras-chave: Ulrich Becher; Stefan Zweig; imagens do Brasil na literatura de língua alemã.

Zusammenfassung: Kaum ein literarisches Werk hat das Brasilienbild so geprägt wie das in den 40er Jahren verfasste Buch von Stefan Zweig Brasilien - ein Land der Zukunft. Trotz des großen Bekanntheitsgrades dieses Buchs und seines harmonischen Brasilienbildes, sollte man nicht übersehen, dass es Bücher von anderen deutschsprachigen Autoren aus derselben Zeit gibt, die uns teilweise gänzlich unterschiedliche Betrachtungen und Interpretationen Brasiliens vermitteln. Im folgenden Artikel behandle ich einige Aspekte des Brasilienbilds im Brasilianischen Romanzero von Ulrich Becher - ein von der Germanistik relativ unbeachteter Autor. U. a. auf Grund seines Bemühens um gute Beziehungen zur Regierung von Getúlio Vargas, tendiert Zweig dazu, mögliche Konflikte zu ignorieren, die die Harmonie, die er in Brasilien gefunden zu haben glaubt, bedrohen könnten. Im Gegensatz dazu hebt Becher - für den dieses Land nur ein vorübergehender Aufenthaltsort war - die Widersprüche und

\footnotetext{
${ }^{1}$ Doutora em Lingüística Aplicada (Tradução) pela Universidade Estadual de Campinas (Unicamp); atualmente docente na área de alemão na Universidade Federal do Paraná (UFPR). Endereço eletrônico: ruth.bohunovsky@uol.com.br.
} 
Gegensätze hervor und betont damit Aspekte, die mit einem Bild der Idylle nicht vereinbar sind, wie die großen sozialen Probleme und Ungerechtigkeiten, und kommt so vielleicht zu einer etwas plausibleren Darstellung Brasiliens.

Stichwörter: Ulrich Becher; Stefan Zweig; Brasilienbild in der deutschsprachigen Literatur.

\section{Introdução ${ }^{2}$}

O livro de Stefan Zweig, Brasil - um país do futuro, publicado pela primeira vez no Brasil em 1941, continua sendo uma referência à qual sempre se recorre quando o tema é este país ou a imagem que dele se faz tanto aqui quanto no exterior. Assim, por exemplo, um documentário sobre o Brasil na importante emissora de rádio austríaca Ö1, em fevereiro de $2008^{3}$, utilizou esse livro como a mais importante referência literária durante as várias horas de sua duração. Como destaca Alberto Dines, no prefácio da última reedição de Brasil - um país do futuro (2006), esse “canto de louvor”, condizente com o projeto de civilização e cultura do seu autor, seria "o mais famoso de todos os textos que se escreveram sobre o Brasil” (DINES, apud ZWEIG 2006: 7 - 9). Entretanto, não se deve entender o imaginário acerca do Brasil descrito nesse livro como sendo representativo para toda a literatura de exílio em língua alemã escrita aqui, principalmente nos anos 1940.

Outros autores de língua alemã, além de Zweig, ficaram no Brasil durante muito tempo, ocuparam-se intensamente com a cultura, a história e outros aspectos marcantes do seu país de exílio, escreveram livros sob a sua influência e, muitas vezes, tiveram impressões e chegaram a conclusões bastante divergentes daquelas que encontramos no famoso livro de Zweig. A seguir - fazendo uma comparação com a imagem do Brasil feita por Zweig -, teço alguns comentários sobre a imagem do país num livro de um desses outros autores: Romanceiro Brasileiro (Brasilianischer Romanzero) ${ }^{4}$ de Ulrich Becher, publicado apenas em 1962, mas escrito quase integralmente nos anos 1940, durante o exílio do seu autor em território brasileiro. Becher é, hoje, um autor pouco lido, raramente discutido e que nunca foi traduzido para o português, mas sua obra não deve ser descartada ao se refletir sobre a construção e a manifestação das diversas imagens do Brasil na literatura de língua alemã, sobretudo porque sua experiência de

\footnotetext{
${ }^{2}$ Agradeço a Klaus Eggensperger pelos valiosos comentários, que ajudaram na elaboração deste trabalho.

${ }^{3}$ http://oe1.orf.at/

4 Todas as traduções citadas neste trabalho cujo tradutor não for mencionado nas referências bibliográficas foram feitas pela autora.
} 
exílio marcou não apenas seus (poucos) trabalhos literários feitos aqui, mas também toda sua obra produzida depois da volta à Europa. Nesse sentido, ao presente artigo interessa menos uma avaliação do valor literário da obra de Ulrich Becher; o maior interesse é dar início a discussões sobre a imagem do Brasil evocada no referido livro.

Ao se propor uma comparação das imagens do Brasil sugeridas em Brasil - um país do futuro, de Stefan Zweig, e no Romanceiro Brasileiro, de Ulrich Becher, não se pode ignorar o fato de que se trata de dois gêneros textuais diferentes (relato de viagem vs. poesia narrativa) e que seus autores vêm de tradições literárias diferentes (humanismo europeu vs. expressionismo). Levando em consideração essas diferenças, parece-me conveniente analisar não apenas os poemas de Becher, mas abordar também as suas "Notas sobre o Romanceiro" (Notizen zum Romanzero) que se encontram no final do referido livro. Nessas "Notas”, o autor oferece - assim como Zweig explicações, descrições e previsões bastante reveladoras no que tange à sua visão particular acerca do Brasil. É na comparação do relato de Zweig com essas exposições de Becher sobre o Brasil que os entrecruzamentos e as divergências entre as imagens do país de exílio construídas pelos dois autores se mostram claramente.

\section{O Brasil em harmonia}

Na introdução de Brasil - um país do futuro, Stefan Zweig - um autor austríaco que, ao longo da sua vida, tratara praticamente apenas de assuntos da história e da cultura européias - confessa que, antes da sua primeira vinda ao Rio de Janeiro, em 1936, suas “expectativas não eram muito altas” (ZWEIG 2006: 13). O autor reconhece que tinha “a mesma imagem algo pretensiosa” do "europeu ou o norte-americano medianos” da época, ou seja, imaginava um país com clima quente e insalubre, politicamente instável e civilizado apenas no litoral - resumindo, “um país, portanto, para emigrados desesperados, mas de modo algum um lugar” do qual se pudessem “esperar estímulos intelectuais” (ibid.). Destaca ainda que “essa imagem” era aproximadamente aquela que vigorava nesses anos "em nossos círculos europeus e norte-americanos” (ibid.). A forma como Zweig escreve não deixa dúvida de que a sua “pequena descrição” (ibid.: 16) do Brasil deve ser entendida como uma tentativa de mudar a suposta ignorância acerca desse país na Europa. Além disso, tem-se especulado muito sobre a relação entre a facilidade com a qual o escritor conseguiu os vistos 
brasileiros para ele e sua esposa e a descrição exageradamente positiva deste país no referido livro. Apesar de ser relevante mencionar mais uma vez o contexto do referido livro, esse aspecto não será abordado neste trabalho ${ }^{5}$.

O Brasil apresentado por Zweig é, em primeiro lugar, um país belo. Logo no início do livro, o autor afirma que, quando chegou ao Rio pela primeira vez, ficou "possuído por um torpor de beleza e de felicidade que excitava os sentidos, crispava os nervos, dilatava o coração, ocupava o espírito”, e quanto mais ele via, “nunca era o bastante” (ZWEIG 2006: 14) ${ }^{6}$. O mesmo livro termina com a frase: “Quem realmente é capaz de sentir o Brasil viu beleza suficiente para a metade da vida” (ibid.: 248).

Aos olhos de Zweig, além de belo, o país é também marcado pela harmonia. Como aponta Dewulf, nesse sentido a descrição do escritor austríaco acerca do Brasil prossegue a tradição “tão típica” (DEWULF 2005: 603) que remonta a Alexander von Humboldt, de relatos de viagem escritos especificamente por autores de língua alemã: ao se referirem ao Brasil, associam descrições de paisagens paradisíacas com o conceito de "harmonia" (ibid.). Ainda na introdução do livro de Zweig podemos ler, por exemplo, que "a disposição harmônica da natureza” no Brasil “passou a ser o modo de vida de uma nação inteira” (ZWEIG 2006: 20). Em outra passagem na qual se refere à cidade do Rio de Janeiro, ele afirma que ali “os extremos divergem muito”, mas, “mesmo assim, misturam-se em uma harmonia especial” (ibid.: 178). Ou, como explica logo depois, "os contrastes entre o velho e o novo, entre a cidade e a natureza, entre ricos e pobres, trabalho e ócio” seriam contrastes presentes na cidade do Rio de Janeiro com os quais “podemos [nos] deleitar em uma harmonia única” (ibid. 179). No trecho em que descreve a sua chegada ao Rio de Janeiro, Zweig repete três vezes o termo "harmonia":

Tudo é harmonia, a cidade e o mar e o verde e as montanhas, tudo se mescla sonoramente, nem mesmo os edifícios, os navios, os letreiros de néon atrapalham, e essa harmonia se repete em acordes sempre variados: a cidade é diferente quando vista a partir dos morros, do mar, mas é sempre harmônica, diversidade dissolvida em unidade sempre completa (...). ZWEIG (2006: 158).

Em outras passagens, pode-se perceber a tendência do autor de ocultar potenciais fontes de conflitos e restabelecer a sensação de harmonia, como num

\footnotetext{
${ }^{5}$ Sobre outros livros de Zweig e sobre os possíveis motivos que o levaram a escrever Brasil - um país do futuro e as diversas especulações acerca do contexto pessoal e político desse livro, cf., por exemplo, KESTLER (2003) ou DiNEs (1981).

${ }^{6}$ Todas as citações do livro Brasil - um país do futuro são provenientes da sua última edição no Brasil, no ano 2006, na tradução de Kristina Michahelles.
} 
parágrafo sobre as favelas e as diferenças sociais na sociedade brasileira transcrito a seguir:

\begin{abstract}
Às vezes quando, curioso, andava pelas favelas, esses pitorescos casebres dos negros que ficam nas encostas dos morros no meio da cidade como gaiolas de pássaros, tive a consciência pesada e um mau pressentimento. Pois afinal eu fora lá por curiosidade para ver o degrau mais primitivo da vida e observar nos barracos de barro e de bambu, indefesos contra todo olhar, as pessoas em sua condição mais primitiva e, com isso, indevidamente espiar para dentro de suas casas e sua vida particular. No início, eu sempre esperava receber um olhar raivoso ou um palavrão pelas costas, como num bairro proletário na Europa. Mas, ao contrário, para essa gente de boa-fé o estrangeiro que se perde naqueles cantos é um hóspede bem-vindo e quase um amigo. O negro que carrega água em baldes sorri com seus dentes brilhantes e ainda ajuda o estrangeiro a subir os degraus de barro escorregadios. (ZWEIG 2006: 131-132).
\end{abstract}

Zweig não vê - ou não quer ver - aspectos que podem por em perigo seu imaginário de um Brasil sempre harmonioso. Isso se mostra não só na inobservância das grandes diferenças entre as diversas classes sociais, como também quando o tema é a natureza. O mato virgem é mencionado por ele apenas tangencialmente, já que não corresponde à imagem que pretende apresentar do país. Ou seja, quando se refere à suposta harmonia entre homem e natureza e a paisagens paradisíacas, o autor comenta apenas aquela natureza já dominada ou cultivada pelo homem. Certamente esta é a parte da natureza do país que mais interessa a Zweig, e a que ele apresenta como paradisíaca e harmoniosa. No pequeno capítulo “Jardins, morros e ilhas”, Zweig discorre sobre a "floresta virgem" que ficaria a "apenas uma hora de distância da cidade” do Rio de Janeiro (ZWEIG 2006: 184) e nos apresenta a seguinte descrição:

A mata aqui não permite, como entre nós, a visão, mas é uma massa compacta e escura e se tentarmos penetrar nela - apenas alguns passos - nos sentiremos presos, isolados como sob um sino de mergulhador; a respiração sente o ar estranho e concentrado como se fosse o hálito quente e úmido de um animal gigantesco e perigoso. (ZWEIG 2006: 184).

A harmonia que procura, Zweig encontra nos jardins, especialmente no Jardim Botânico - que, nas suas palavras, seria "um museu” e, ao mesmo tempo, "um pedaço completo de natureza” que permitiria "a ilusão de que essa vegetação continua daqui, do meio de um parque e de uma metrópole, mais e mais para o interior” (ZWEIG 2006: 185). A imagem que o autor constrói da natureza brasileira enfatiza essa "ilusão" de uma paisagem perfeita na qual "existe tudo que a mata virgem contém, mas sem sustos - sua infinitude, a impenetrabilidade, seus perigos” (ibid.: 184). O escritor não se 
interessa pelos possíveis "perigos” e "sustos" que a natureza selvagem poderia lhe causar e exalta, muito mais, os projetos paisagísticos e a natureza cultivada, a "aléia de palmeiras” que seria “magnificamente simétrica e firme como as colunas de um templo grego milenar” (ibid.: 185), os lagos e terraços dos jardins e, por fim, um aspecto que provavelmente não encontraria nem na cidade, nem na mata virgem: o "grande silêncio" (ibid.: 186).

Além dos jardins, Zweig vê beleza também na paisagem carioca quando vista de longe - dos topos dos morros e dos barcos -, e nas pequenas ilhas. São distâncias e tamanhos que permitem a impressão de se poder controlar o que se enxerga e fugir dos "sustos” da mata virgem (ibid.: 186-187). Assim, os poucos momentos nos quais Zweig menciona a natureza selvagem do Brasil e seus possíveis perigos não chegam a pôr em dúvida o imaginário que ele cria acerca desse país e da sua natureza.

A suposta harmonia que Zweig acredita ter aqui encontrado entre "uma nação inteira” e a natureza - assim como a suposta harmonia racial - não pode ser abordada sem que sejam lembradas as lamentações que o autor formulou simultaneamente sobre a destruição irreversível do seu "mundo de ontem" europeu. Apesar disso, o olhar de Zweig acerca do Brasil pode ser entendido também na tradição dos "mitos de paraíso" (SousA 1996: 48), que se caracterizariam, entre outros aspectos, pela procura de completude, pelo destaque da beleza ímpar das paisagens, da tranqüilidade, das imensas riquezas potenciais e, por fim, pela oposição às características da Europa (SoUSA 1996: 209).

De acordo com SousA (1996), descrições de paisagens brasileiras baseadas em “mitos do paraíso/idade de ouro e Eldorado” são freqüentes na literatura de língua alemã que aborda o Brasil, assim como também, na literatura dos imigrantes alemães cujos primeiros representantes chegaram ao Brasil na virada do século XIX para o século XX. De acordo com Valburga Huber (2005), na produção literária desse grupo étnico, desde a primeira geração (ainda nascida na Alemanha) até a terceira, a imagem do Brasil é freqüentemente edênica. No seu artigo, Huber cita, por exemplo, a seguinte passagem do poema "No planalto” (Im Hochland), de Georg Knoll, para ilustrar esse imaginário - uma passagem que dá a entender, também, uma adaptação pouco refletida da tradição discursiva acerca de características da primavera européia numa realidade climática tão diferente como a do Brasil: 


\author{
Docemente corre o rio pelas verdes \\ Campinas \\ E em toda a parte, os rastros da primavera \\ Um ressuscitar no campo e no mato. \\ O ar é puro, o céu azuleja. \\ Sanft fließt der Bach durch grüne \\ Fluren \\ Und überall des Frühlings Spuren \\ Eine Aufersteh'n in Feld und Hain. \\ Die Luft ist rein, der Himmel blauet.
}

(KNOLL 1923; in: HuBer 2005: 655).

\title{
3. A harmonia em questão: o Brasil de Ulrich Becher
}

Apesar da predominância de descrições paradisíacas do Brasil na literatura alemã de exílio e/ou de imigração (SousA 1996), seria incorreto supor que essa seja a única tendência de representação desse país nesse gênero literário. Vale ressaltar desde já que, nesse contexto, a imagem do Brasil talvez não seja o único aspecto que mereceria uma atenção maior. Há outras particularidades que poderiam ser estudadas, ainda que, às vezes, estejam presentes em textos de escritores pouco conhecidos tanto nos países de língua alemã quanto no Brasil, onde quase nunca se encontram traduções de seus livros. A potencial relevância dessa literatura de exílio para os estudos germânicos já foi destacada, por exemplo, por Jeroen Dewulf (2007), em seu artigo "Hubert Fichte vorweggenommen. Die afrobrasilianischen Religionen bei den Exilautoren Richard Katz und Ulrich Becher". De acordo com esse germanista, embora nenhum outro autor alemão tenha conseguido descrever de maneira tão convincente como Hubert Fichte o momento "mágico" do transe no candomblé brasileiro, não se deve esquecer que

\footnotetext{
dois autores alemães exilados, Richard Katz e Ulrich Becher, que tiveram bastante sucesso durante suas vidas, mas cujas obras têm sido neglicenciadas desde sempre pelos estudos germânicos, enfrentaram esse mesmo desafio de Fichte muito tempo antes e apresentaram soluções que anteciparam duas das idéias básicas dos “ethno-poetics” de Fichte (DEWULF 2007: 31).
}

Em outro trabalho, DEWULF salienta a “imagem divergente do Brasil” (2005: 603) que Richard Katz elaborou em vários livros durante os anos em que esteve no Brasil. O conceito de “divergente”, no caso, refere-se justamente à postura crítica de Katz em relação à suposta "harmonia" presente, por exemplo, no referido livro de Stefan Zweig. Nos seus primeiros textos feitos no Brasil, Katz ainda parece ter sido 
marcado por um imaginário baseado no conceito de harmonia entre natureza e cultura, mas sua percepção foi mudando ao longo do tempo (DEwUlf 2005). Depois de exilarse no Brasil com planos de ficar e, mais tarde, adotar a nacionalidade brasileira, Katz apresenta descrições mais diferenciadas do país e adverte sobre os perigos do racismo que, aqui também, existiria (Dewulf 2005: 605). Desse modo, Katz alcança "uma maturidade (...) que falta no estudo de Zweig sobre o Brasil” (DewUlF 2005: 604), sobretudo no que diz respeito à sua visão da “democracia racial” do país (ibid.).

Dewulf chama a atenção também para a ausência do nome de Richard Katz mesmo em muitas obras de consulta sobre literatura de exílio (DEWULF 2005: 608), apesar de esse autor ter sido um dos mais lidos da Alemanha (ibid.: 604) nos anos 1920 e 1930. Embora tenha sido considerado, por Erich Maria Remarque, um autor que “revolucionou” a literatura de viagem e "renovou clichês gastos” (ibid.: 608), depois da sua morte, poucos têm lembrado o seu nome.

Há alguns paralelos entre o destino de Richard Katz e o de Ulrich Becher, tanto na vida quanto na literatura sobre o Brasil e também no que tange ao esquecimento de seus nomes. Filho do advogado alemão Richard Becher e da pianista suíça Elisabeth Ulrich, Becher, ainda jovem, casou-se com Dana, a filha do autor austríaco Alexander Roda Roda, e se mudou para Viena. Mudou também de nacionalidade, tornando-se austríaco. Sua esperança de poder fugir do nazismo e exilar-se na Suíça devido ao fato de ser filho de uma suíça não se realizou, pois sua postura claramente antinazista infringiu o princípio de neutralidade daquele país. A polícia de emigração negou-lhe a permissão de trabalho e sugeriu que ele emigrasse para outro lugar. Em 1941, Ulrich Becher e sua esposa conseguiram fugir do nazismo via França, Espanha e Portugal, instalando-se finalmente no Brasil. Aqui, além de publicar alguns artigos jornalísticos no Estado de São Paulo, em 1943, Becher escreveu quatro das cinco baladas da narrativa em verso Romanceiro Brasileiro (Brasilianischer Romanzero) e também a maior parte do romance em versos Franz Patenkindt: Romance de um Afilhado Alemão de François Villon (Franz Patenkindt: Romanze von einem deutschen Patenkind des François Villon), publicado apenas em 1979. Diferentemente de Zweig, Becher viu no Brasil apenas um lugar de passagem e, durante três anos, tentou um visto para os EUA, onde finalmente se estabeleceu com sua esposa, em 1944, e onde nasceu seu filho Martin Roda Becher (hoje também escritor). Depois da guerra, o casal voltou para a Europa e morou em Basel, onde Becher faleceu em 1990. 
Em 1957, Becher foi definido como um escritor “de peso médio” pela revista alemã Der Spiegel (1957), mas hoje, assim como Katz, está “injustamente esquecido e raramente [é] mencionado em histórias da literatura” (KESTLER 2003: 76). Uma das suas obras, porém, ficou inesquecível, pelo menos para a população austríaca: Der Bockerer, originalmente uma peça teatral de sua autoria em conjunto com Peter Preses, que entre os anos 1981 e 2003 foi levada às telas do cinema por Franz Antel, numa série de filmes com o mesmo nome. Apesar do grande sucesso desses filmes, raramente associa-se Der Bockerer ao nome de Ulrich Becher; os nomes sempre lembrados em relação a esse título são os de Franz Antel, diretor da filmagem, e Karl Merkatz, o ator que representou o personagem principal nas telas.

A relevância do exílio na obra de Ulrich Becher é inegável. Suas experiências desse período transparecem não apenas nos livros que escreveu durante a época em que viveu distante da Europa. Mais do que uma influência natural e até inevitável, essas vivências devem ser vistas como a “força matriz" (KESTLER 2003: 213) para seus trabalhos durante muitos anos depois. É pertinente mencionar também que o herói nos seus livros é, muitas vezes, um "peregrino que se lança em aventuras e ao mesmo tempo teme o mundo e a natureza desconhecida” (ibid.: 219) e geralmente possui “evidentes traços autobiográficos” (ibid.). Como um “peregrino” Becher deve ter-se sentido durante sua estada no Brasil, já que vivia tentando obter um visto para os Estados Unidos, um país considerado mais “civilizado”. Essa situação de Becher - tão diferente daquela de Zweig - certamente influenciou o seu olhar e a sua produção literária acerca do país. Nesse sentido, vale citar uma passagem do poema "Romance do Encontro com João Damasceno Baunilha” que termina o primeiro parágrafo com as seguintes palavras:

(...) nesse país, fui um andarilho cansado do cansaço.

Fui um andarilho no país, jamais alguém que ficou.

(...) war in dem Lande ein Müdeseins müder Wanderer.

War in dem Land ein Wandrer, ein Bleibender nie. (BECHER 1962: 85). 
O livro Romanceiro Brasileiro $^{7}$ é um poema narrativo, dividido em cinco romances de diferentes extensões: o primeiro, "Romance dos Cães Raivosos do Rio” (“Romanzero von den tollen Hunden zu Rio" ${ }^{\text {) }}$ ), e o último, "Romance do Encontro com João Damasceno Baunilha” (“Romanze der Begegnung mit Johann Damaszener Vanille”), são mais longos; os restantes ocupam apenas poucas páginas: "Romance da Floresta Estranha” (“Romanze vom fremden Wald”), “Romance da Árvore Vermelha, Pau-brasil” (“Romanze vom roten Baum”) e "Romance da Morte do Beija-flor" (“Romanze vom Blumenküssertod”). A linguagem das poesias é, em sua maior parte, barroca e de estilo nervoso, desafia a ordem sintática do alemão e está carregada de neologismos. Além disso, contém muitos empréstimos (vira-lata, pinga, morro, Cantagallo etc.) e traduções “literais” do português brasileiro para o alemão (Schwarzes Gold [Outro Preto], Richter-von-draußen [Juiz de Fora]), com respectivas explicações didáticas nas "Notas sobre o Romanceiro", no final do livro. Essas características da linguagem usada em suas poesias parecem ter se fortalecido em obras mais tardias, haja vista as críticas da época. A linguagem de seu romance Logo depois das quatro (Kurz nach Vier), de 1957, foi qualificada como “intencionalmente desarmônica e de um barroco esnobe” (in: Der Spiegel, 1957²) e a de Caça às bolinhas de gude (Murmeljagd), de 1969, como “exótica” (Martin Gregor-Dellin, in: Die Zeit, 1969). Embora se possa afirmar que no Romanceiro Brasileiro Becher também seja “apaixonado no seu vocabulário e na sua exótica febre narrativa” - como Gregor-Dellin comenta em relação ao estilo de Caça às bolinhas de gude (1969) -, ele não perde “o chão embaixo de seus pés" (ibid.) e a leitura não se torna excessivamente "cansativa e semelhante a um trava-língua” (ibid.). KESTLER frisa que nas obras anteriores ao exílio, o estilo de Becher, "apesar da influência expressionista”, era "relativamente descolorido” (2003: 221). Depois da sua vinda ao Brasil, sua escrita “caracteriza-se pela

\footnotetext{
${ }^{7}$ Com este título, Romanceiro Brasileiro (Brasilianischer Romanzero), Becher talvez tenha pretendido remeter à coletânea de poemas Romanceiro (Romanzero) de Heinrich Heine, publicada pela primeira vez em 1851. Esta coletânea contém, entre outras “histórias”, um poema narrativo cuja temática é o Novo Mundo: "Vitzliputzli”, que trata, especificamente, do fim do império asteca depois da invasão dos espanhóis na península Yucatán. Além deste, há outros paralelos que permitem pensar em uma possível referência intertextual. Como salienta Kestler, Becher costuma seguir modelos ao elaborar os próprios livros (KESTLER 2003: 214). No âmbito deste artigo não há possibilidade de se fazer uma discussão mais aprofundada sobre esse ponto, mas gostaria de chamar a atenção, por exemplo, para o enfoque dado, pelos dois autores, às dissonâncias, às contradições, aos contrastes (ascensão vs. decadência, vida vs. morte, o mau vs. o bom, o bonito vs. o feio) e para a crítica social que os dois escritores - ambos fora dos mainstreams literários dos seus tempos - empreendem.

${ }^{8}$ Para os títulos dos romances do referido livro de Becher, sigo aqui as traduções de Kestler (2003: 217).

${ }^{9}$ Não consta o nome do autor deste artigo no site onde ele se encontra disponível (cf. referências).
} 
inclusão do ambiente colorido, exuberante, da floresta virgem brasileira, e sua linguagem adquiriu novas intensidades de expressão, descritas por Becher e pela crítica como Urwaldbarock [barroco da floresta virgem]” (ZELLER 1983: 58, apud KeSTLER 2003: 221).

Assim, o Romanceiro Brasileiro, mais que qualquer outro trabalho de Becher feito no Brasil e sob a influência tropical, é o resultado de uma "aproximação profunda, lingüística e espiritualmente, com uma paisagem cultural completamente diferente” (Kestler 2003: 217). Dewulf concorda com o pensamento de Kestler de que, de todos os autores exilados, Becher seria aquele que mais se inspirou nas experiências brasileiras para criar temas e motivos para sua obra (DewUlf 2007: 39). No Romanceiro Brasileiro, Becher não esconde sua fascinação pelo país: “Ainda sonho todo dia, toda noite, com esse país. Nunca vi outro tão inesquecível” (“Träume noch jede Nacht, jeden Tag von dem Land. Hab ein so unvergeßliches nimmer gekannt”) (BECHER 1962: 111). Mas, Becher deixa também a impressão de não conseguir entender tudo do que viu nesse país denominado por ele de maneira significativa "Nunca-meconheces-inteiramente” (“Kennstmichnieganz”) (BECHER 1962: 83), onde tudo seria estranho e diferente, como podemos ler em seu comentário nas "Notas sobre o Romanceiro": “No Brasil, quase tudo é diferente!” (“In Brasilien ist fast alles anders!”) (ibid.: 120). O autor menciona também repetidamente o fato de que, no Brasil, o galo canta antes de meia-noite - o que seria um fenômeno "sem sentido" e "enigmático" (ibid.: 121). É justamente esse fenômeno "sem sentido” e "enigmático” que o autor utiliza em vários momentos para caracterizar e simbolizar o Brasil, isto é, o país onde “o galo canta antes de meia-noite“ (ibid.: 83, 84, 120).

Na tradição do expressionismo alemão, Becher aborda em seus poemas temas como a morte, a solidão, doenças, a destruição, a decomposição, o feio e o cruel. Na interpretação do Romanceiro brasileiro feita por SoUSA, apenas a paisagem urbana em claro contraste com a natureza - foi apresentada pelo autor como "lugar infernal, em que a miséria prolifera” (1996: 74). Desse modo, ainda de acordo com SousA, a imagem que Becher apresenta da natureza brasileira representaria, como em tantos outros livros de diversos autores de língua alemã, uma manifestação dos "mitos da conquista”, evocando “a imagem do Jardim do Éden” (ibid.: 74). Embora o mencionado livro de Sousa seja, sem dúvida, uma referência fundamental e uma leitura obrigatória para quem pretenda pesquisar a imagem do Brasil na literatura de língua alemã, tendo a discordar da argumentação da autora nesse ponto. No meu entender, Becher realmente 
utiliza imagens recorrentes de caráter paradisíaco para descrever a natureza brasileira, mas utiliza adjetivos que não remetem necessariamente a um imaginário paradisíaco. A título de ilustração desse argumento, cito uma passagem do início do primeiro poema:

Nos Estados Unidos do Brasil,

Os cães selvagens passam ao longo dos rios

Vadiam ao longo dos rios amarelos de lama, marrons de excrementos,

Caçando impiedosamente em matilhas conspiradoras.

In den Vereinigten Staaten Brasiliens

Ziehen die wilden Hunde den Flüssen, streunen den lehmgelben kotbraunen Flüssen

wildernd entlang in verschworenen Rudeln. (BECHER 1962: 9).

Além dos verbos que dizem respeito aos cães, “vadiam” (“streunen”) e “caçando” (“wildern”), são também os adjetivos que informam sobre a qualidade dos rios, “amarelos de lama” (“lehmgelb”) e "marrons de excrementos” (“kotbraun”) que não combinam com descrições de uma paisagem supostamente edênica. Não seria apenas o meio urbano que é atravessado pelos rios “amarelos de lama” e "marrons de excrementos”, mas o país inteiro, até a selva (ibid.: 10). Nas imagens evocadas pela poesia de Becher, a degradação nas cidades é certamente maior, mas o impacto negativo da ação humana se faz sentir também nas áreas rurais, ou seja, na natureza do país, em todos os “Estados Unidos do Brasil”. A própria expressão “Estados Unidos do Brasil” já sugere que a "civilização" tenha se sobreposto à natureza intacta que aqui um dia, talvez, tenha existido. Nesse sentido, parece-me interessante também o fato de Becher dedicar a maior parte do seu livro a cães, ainda mais a cães famintos, raivosos, doentes e sujos - e não a um animal tradicionalmente associado a imagens paradisíacas. Embora os cães sejam, geralmente, animais associados com a paisagem urbana no Brasil, Becher estende o espaço habitado por eles e os apresenta como moradores "mesquinhos, magros, depravados” da selva (ibid.: 10).

Ainda no mesmo poema, Becher retrata mais detalhadamente também outros moradores da selva brasileira. Considerando a análise feita por SouSA, sem dúvida alguma, essa floresta de Becher seria o habitat de uma variedade de animais (de tucanos, araras, pica-paus, cobras, coelhos, jacarés e pássaros), que poderiam evocar “a imagem do Jardim do Éden” (SoUSA 1996: 74). No entanto, são novamente os verbos e adjetivos que acompanham esses nomes que sugerem uma sensação de ameaça, de uma harmonia enganadora e de lutas injustas entre representantes da fauna brasileira com forças desiguais. Assim, os bicos dos tucanos seriam “colossais” (“ungeheuer”), a arara chama de maneira “estridente como conversa de comadre” (“altweiberschrill”), os ruídos feitos 
pelo pica-pau “ribombam” (“dröhnen”) pela selva, as cobras com cinco metros de tamanho "cercam” (“umzingeln”) os coelhos que dormitam e, portanto, não suspeitam de nada, e os jacarés nadam “de barriga para cima” (“rücklings”), se incham ou chocam no canavial fumegante, catados por pássaros. As primeiras linhas do "Romance do encontro com João Damasceno Baunilha”, que lembram o início do "Romance dos Cães Raivosos do Rio”, também reforçam minha argumentação:

Muitos rios amarelos atravessam o país sem fim.

Sempre quando vinha a chuva, eles levavam um amarelo de estrume.

Dentro deles boiavam hortênsias murchas e ratos bem mortos

e cadáveres de cães, cor de laranja.

Viele gelbe Flüsse durchwallen das Land ohne Ende.

Stets wenn der Regen kam, führten sie jauchiges Gelb.

Drin trieben welke Hortensien und maustote Ratten

und orangenfarbene Hundekadaver. (BECHER 1962: 85).

Ao referir-se à degradação da natureza em todas as áreas do país, já que os "rios amarelos” não se encontram apenas nas cidades, mas "atravessam o país sem fim”, essa passagem - assim como muitas outras no mesmo livro - certamente não faz lembrar cenários paradisíacos, mas evoca imagens destrutivas no sentido expressionista. No "Romance da Morte do Beija-flor”, o eu lírico até associa a selva com a "loucura”, ou seja, com a perda da memória, ou, talvez mesmo, com uma ameaça à própria saúde mental:

Como numa peneira, minha memória se foi.

Mariposas noturnas enormes sussurraram para mim: "Fique e se acomode!"

Mariposas diurnas enormes, azul como o céu, pó de ouro no meio,

Arrepelam um véu em frente do pulular e da espreita da selva,

Que me enrosca com flores ardentes de loucura.

Wie durch ein Sieb, so rann mir Erinnerung aus.

Riesennachtfalter beraunten mich: „Bleib und versäume!“

Riesentagfalter, himmelblau, Goldstaub die Mitte, zupften mir Schleier von Dschungels Wuchern und Lauern, der mich umrankte mit flammenden Blumen des Wahns. (BECHER 1962: 83).

Ainda no mesmo poema, o narrador descreve um beija-flor com as seguintes palavras: “o companheiro mais gracioso criado até hoje pela lenda que canta a beleza” (“ziersten Gespielen, den je ein Schönheit besingendes Märchen erschuf’) (BECHER 1962: 83). E continua a descrever a cena, relatando que, de repente, “avança Aquilo do céu” (“stieß Das vom Himmer”), um salteador, quase invisível, com um grasnido 
estridente - e do beija-flor sobra apenas "uma pena minúscula” que cai, suavemente, na mão do narrador, “como uma súplica por memória” (“Und aus dem Himmel sank mir wie ein Flehn um Gedenken so ein ganz winziges Federchen sanft auf die Hand") (ibid.: 83-84). Depois de encantar o leitor com a beleza e o encanto do beija-flor, o autor termina assim o poema sobre a morte súbita do beija-flor, mais uma vez, com uma alusão ao absurdo do Brasil, isto é, ao fato de que, no Brasil, o galo canta bem antes de meia-noite (ibid.: 84).

O “Romance da Árvore Vermelha, Pau-brasil” é, em minha opinião, o único no referido livro de Becher que, nos primeiros versos, permite uma associação com um imaginário enraizado em mitos paradisíacos do Brasil, como ilustra a seguinte citação:

Tivemos um sonho:

conhecemos uma árvore com plumagem púrpura, com um corpete de cipó.

Conhecemos um arbusto, sua folhagem fumaça azul, sua flor enfeite dourado brinco de ouro de menina bonita.

(...) Circulam gaivotas no traje ocre do leão nas serpentes verdes das ondas. Um suspiro sonolento duvidando se a tanta beleza se acostuma o olhar sonhador!

Wir hatten einen Traum: wir kannten einen Baum mit purpurnem Gefieder, Lianenhang sein Mieder.

Wir kannten einen Strauch, sein Blattwerk blauer Rauch, die Blüte Goldgepräng, Schönmädchenohrgehäng.

(...) Vagabundieren Möwen im ockern Kleid des Löwen auf grünen Wellenschlangen. Ein Seufzen, schlafbefangen

Zweifelnd, daß soviel Schöne

Dem Traumblick sich gewöhne! (BECHER 1962: 80-81). 
Porém, a impressão de beleza natural deslumbrante e pacífica é enganadora, parece ser apenas uma superfície de um sonho abaixo da qual se esconde um pesadelo, como sugerem os versos da segunda parte desse curto romanceiro:

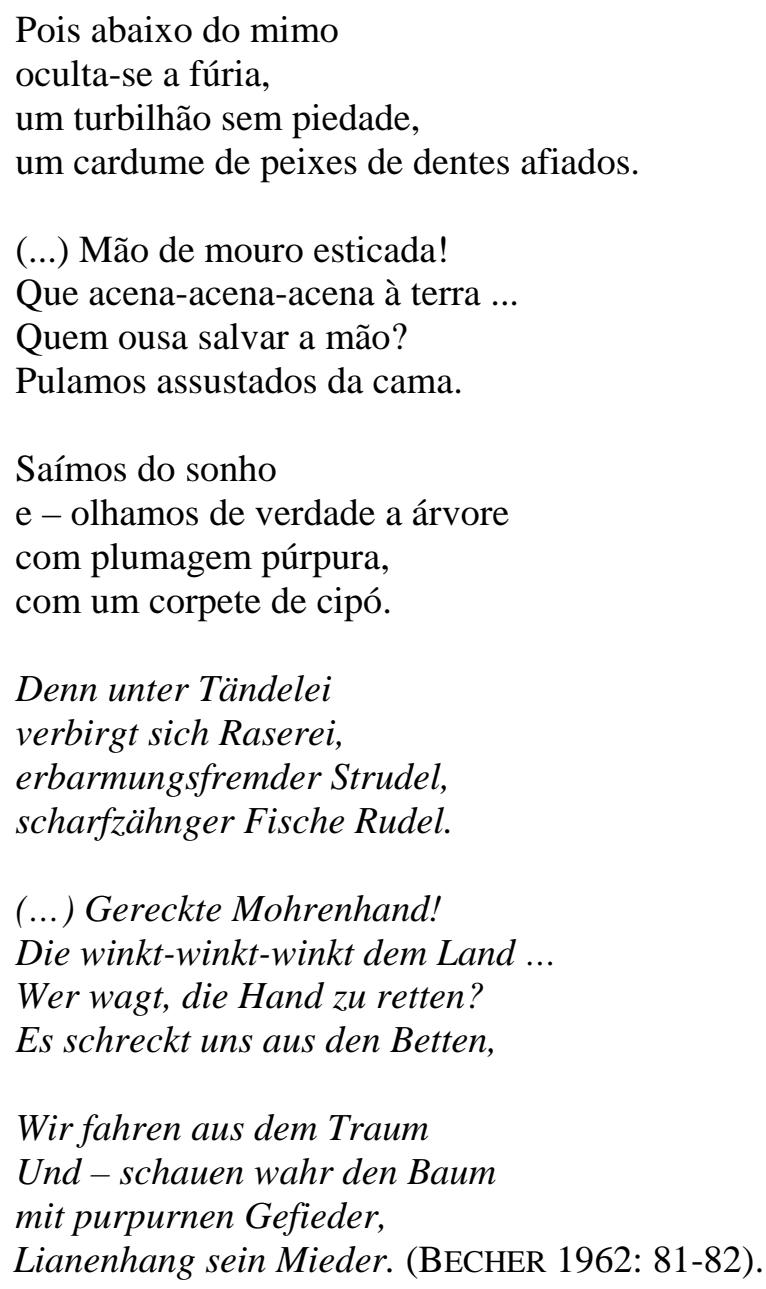

Em relação à população brasileira, Ulrich Becher focaliza sua atenção nos pobres, nos negros, nos andarilhos e vagamundos, nos índios, nos moradores de favela que - muito diferentes do negro que "sorri com seus dentes brilhantes e ainda ajuda o estrangeiro a subir os degraus de barro escorregadios” (ZWEIG 2006: 132) - são vítimas da raiva (BECHER 1962: 13-25), da fome e de muitas doenças, e cuja existência se assemelha com as vidas de cães vira-latas (ibid.: 116). Conforme já apontou Sousa, a paisagem urbana em geral é associada por Becher às características de um "lugar infernal” cheio de miséria (1996: 74), um lugar decadente pela ação humana - que, porém, estende essa decadência país afora. A seguinte passagem ilustra bem essa afirmação: 


\author{
No morro da Babilônia \\ vivem os pobres em casas de abelha. \\ Na verdade, uma colméia abandonada, \\ na qual se aninhou um bulício não alado. \\ Olhem. Como um asilo de minhocas, apresenta-se \\ o morro babilônico para o observador nas profundezas \\ do colégio militar. Mas ao subir lá, \\ ele precisa pedir muitas desculpas \\ ao seu nariz \\ e admitir: mas aqui vivem seres humanos. \\ Auf dem Morro der Babylonier \\ hausen die Armen in Bienenwaben. \\ Wahr, als verlassener Bienenkorb, \\ drein sich unflügges Gewimmel genistet, \\ seht, als Würmerasyl präsentiert \\ sich der Babylonische Hügel \\ dem sinnierenden Betrachter in Tiefen \\ des Militärkollegiums. Doch klimmt \\ jener empor, muß er ach seine Nase \\ vielmals um Entschuldigung bitten \\ und sich gestehn: Hier wohnen ja Menschen. (BECHER 1962: 25-26).
}

Nas “Notas sobre o Romanceiro”, Becher descreve a composição da população brasileira apontando que a sua grande maioria seria composta de "pequenos camponeses de pobreza inimaginável” (BECHER 1962: 116) e toca em assuntos como o grande analfabetismo (ibid.: 117), a malária (ibid.: 118), a grande mortalidade infantil que, na época, chegava a 40\%, ou mais, no Rio de Janeiro (ibid.: 119), a sífilis (ibid.: 121), a peste (ibid.: 122) e a miséria (ibid.: 123). São esses assuntos que predominam tanto nos seus poemas quanto nas notas explicativas no final do livro.

Como já argumentei acima, o desejo de Stefan Zweig de ver harmonia manifesta-se não apenas em passagens que tratam da natureza brasileira e do convívio entre homem e natureza, mas também nas suas interpretações da convivência humana em geral. De acordo com esse escritor, no Brasil, mais que em qualquer outro país do mundo, concretizou-se uma harmonia racial, "uma convivência pacífica entre as pessoas apesar da diversidade de raças, classes, cores, religiões e convicções” (ZWEIG 2006: 17). De acordo com Dewulf, essa suposta harmonia é colocada em questão por Katz, que apresenta uma "visão da democracia racial brasileira bem mais diferenciada do que aquela que encontramos em Zweig” (2006: 606). A visão de Katz é mais pessimista e adverte sobre os perigos do racismo, que no Brasil também existe (DEWULF 2006). Nesse contexto, é surpreendente observar que Ulrich Becher, apesar de enfocar com freqüência vários aspectos da miséria brasileira nos seus poemas, quando se refere 
explicitamente ao problema racial, nas "Notas sobre o Romanceiro", destaca que aqui “não existem presunções ou preconceitos raciais", o que "na história futura das duas Américas” ainda se mostrará como "um grande ponto positivo do Brasil” (BECHER 1962: 121). Algumas linhas depois, ele repete: "Mais uma vez, o problema racial, do qual sofrem os Estados Unidos, é inexistente no Brasil” (ibid.: 123). Pode-se concluir que, para Becher - assim como para Zweig, porém diferentemente de Katz -, a existência de enormes conflitos raciais em outros lugares do mundo parece tornar insignificantes os problemas raciais que certamente existiam (e ainda existem) no Brasil. As diferenças sociais entre os diversos grupos étnicos do país transparecem tanto no referido livro de Zweig quanto no de Becher, no entanto não são abordadas de maneira crítica pelos autores.

Em geral, Becher mostra claramente o fascínio que sente pelo país, que seria “inesquecível” (BECHER 1962: 111). Ele não revela, porém, o que mais lhe provocava tal fascínio, se os fatores positivos ou os negativos - ou talvez justamente a coexistência dos extremos. É importante ressaltar também que, muito diferente do que faz Zweig, Becher não se propõe a apresentar uma imagem clara ou uma descrição pretensamente objetiva do Brasil. O caráter poético do livro acentua ainda mais a ambigüidade e dá relevo à possibilidade de interpretações diversas.

No meu entender, Becher está longe de oferecer uma visão harmoniosa, pacífica ou edênica do Brasil, nem mesmo da natureza e de lugares rurais, conforme sugere Sousa (1996). Ao contrário, a harmonia e a beleza do país parecem estar em permanente perigo, nunca plenas e sem ressalvas. Nesse mesmo sentido pode-se entender também a seguinte passagem do livro (mais uma vez nas "Notas sobre o Romanceiro”), na qual Becher descreve as flores dos ipês caracterizando-as como “fantásticas” e “maravilhosas”, mas associando-as também ao adjetivo “doentio”:

Essas 'flores enormes' que, em seu esplendor de contos de fada verdadeiramente maravilhosas, parecem ao europeu como degeneradas, quase doentias, simbolizam aqui, na memória do autor deste romanceiro, o país gigantesco, apenas uma parte daquilo que 'virá a ser', no qual o galo canta antes de meia-noite.

Diese den Europäer unwahrscheinlich und in all ihrer wahrhaft wunderschönen [sic.] Märchenpracht wie entartet, fast krankhaft anmutenden 'Riesenblumen' stehn im Gedenken des Romanzenschreibers als Sinnbild des riesengroßen, erst zu einem Bruchteil 'gewordenen' Landes, wo der Hahn vor Mitternacht kräht. (BECHER 1962: 120). 
É interessante observar que, dependendo do entendimento sobre o fato de Becher se incluir - ou não - no grupo de “europeus” ao qual se refere, há duas interpretações possíveis para esse trecho. Ou ele se vê como europeu e entende as flores - enigmáticas entre seu "esplendor de contos de fada verdadeiramente maravilhosas" e sua natureza - “degeneradas, quase doentias” - como um símbolo desse país absurdo, onde o galo canta antes de meia-noite; ou ele faz questão de se distanciar da visão comum ao "europeu”, ressaltando o "esplendor maravilhoso" das flores e, ao mesmo tempo, do Brasil. As duas leituras podem ser feitas, e, no meu entender, é justamente essa dualidade que o autor vive que o faz enxergar contrastes em tudo e que permeia os poemas do Romanceiro Brasileiro.

\section{Comentários finais}

Zweig e Becher escreveram sobre o Brasil durante o período em que viveram no país, o que ocorreu praticamente na mesma época, porém em circunstâncias diversas. Os livros Brasil - um país do futuro e Romanceiro Brasileiro nos apresentam dois "Brasis” diferentes. Nenhuma dessas imagens deve ser entendida como um "retrato fiel” da “realidade” do país. No entanto, elas nos revelam muito sobre as concepções de mundo e sobre as tradições literárias dos autores. Apesar das diferenças que foram apontadas ao longo deste artigo, é interessante que sejam mencionadas também as semelhanças entre dois imaginários: assim como Zweig, Becher define o Brasil como um país onde não existem conflitos raciais e, além disso, denomina o Brasil um país do futuro, ou seja, como um país pronto apenas em parte ("erst zu einem Bruchteil 'gewordenen') (BECHER 1962: 120). Certamente, o porvir antevisto por Becher é bastante diferente daquele com o qual sonha Zweig acreditando na natureza pacífica do brasileiro e confiante em um futuro promissor e sem violência do país. Nas "Notas sobre o Romanceiro", ao versar sobre a grande pobreza da população rural e os movimentos de sem-terra da época, Becher menciona que acredita na iminência de uma revolução social e agrária: "àquele que, nos anos quarenta, redigiu este romanceiro, parece hoje que a proverbial paciência do povo brasileiro esteja, lentamente, chegando ao seu fim” (“Dem, der in den Vierziger Jahren diesen Romanzero verfaßte, will heute scheinen, daß paciência, die sprichwörtliche Geduld des brasilianischen Volkes, langsam am Erlöschen sei”) (BECHER 1962: 116). Tanto Zweig quanto Becher parecem 
ver um futuro promissor para o Brasil. No entanto, baseados em posturas ideológicas distintas, entendem algo diferente com isso.

Como exclama o próprio Becher, nas “Notizen zum Romanzero” (Notas sobre o Romanceiro): “No Brasil, quase tudo é diferente!” (“in Brasilien ist fast alles anders!”) (BECHER 1962: 120). Cabe aqui ainda a pergunta: Diferente de quê? Da Alemanha? Da Áustria? Da Suíça? Da Europa? A meu ver, não é apenas nesse sentido que o poema de Becher pode ser entendido, ou seja, como mais um testemunho de que no Brasil tudo seria diferente do velho mundo. Apoiado na tradição literária do expressionismo e nas próprias observações e vivências, Becher nos apresenta um Brasil que é diferente daquele imaginado por Zweig e por outros autores orientados por imaginários mais idílicos e paradisíacos. As incongruências em relação aos imaginários acerca do Brasil parecem ser justamente o tema da peça de teatro Samba, escrita por Becher depois da sua volta à Europa. De acordo com Sousa, nessa peça,

[o] Brasil funciona (...) como o espaço onde poderia ser possível viver em segurança, isto é, fora do alcance dos nazistas, longe da atmosfera de guerra e falta de liberdade que marcam a Europa. É assim que o começo da peça deixa entrever a imagem do Brasil, projetada através das personagens e do cenário.

(...) As personagens, por sua vez, mostram não ter tido uma idéia clara do Brasil, antes de aqui aportarem. Parecem, pelas declarações que fazem, presas a uma imagem fantasiosa de nosso país, cuja realidade, no entanto, as decepciona. (SOUSA 1996: 96-97).

Por fim, gostaria de ressaltar ainda que, até hoje, há poucas pesquisas sobre a vida e a obra de Ulrich Becher, tanto no Brasil quanto nos países de língua alemã. Certamente, traduções dos seus livros e a realização de pesquisas acadêmicas mais aprofundadas sobre a influência do contato com o Brasil em sua obra, assim como sobre as implicações de seus textos para a construção do imaginário sobre o Brasil, poderiam ser não apenas um interessante desafio para um tradutor ou pesquisador, mas também de interesse para os estudos germanísticos no Brasil.

\section{Referências bibliográficas}

s.n. „Ulrich Becher: Kurz nach 4“. In: Der Spiegel, Hamburgo, 27/03/1957, 52. http://wissen.spiegel.de/wissen/dokument/dokument.html?id=41120911\&top=SPIEGEL (03/07/08). 
BeCHer, Ulrich. Franz Patenkindt: Romanze von einem deutschen Patenkind des François Villon in fünfzehn Bänkelsängen. Munique, Universitas, 1979.

BECHER, Ulrich. Murmeljagd. Reinbek, Rowohlt, 1969.

BECHER, Ulrich. Brasilianischer Romanzero. Hamburgo, Rowohlt, 1962.

BECHER, Ulrich. Kurz nach 4. Hamburgo, Rowohlt, 1957.

BECHER, Ulrich. Samba. Viena: Universal Edition, 1950. In: Spiele der Zeit. Hamburgo, Rowohlt, 1957.

DEWULF, Jeroen. Hubert Fichte vorweggenommen: Die afrobrasilianischen Religionen bei den Exilautoren Richard Katz und Ulrich Becher. In: Monatshefte, Vol. 99, No. 1, Wisconsin, 2007, 31-51.

http://muse.jhu.edu/demo/monatshefte/v099/99.1dewulf.html (12 /06/ 2008).

DewUlF, Jeroen. Brasilien sollte kein Land der Zukunft werden. Das abweichende Brasilien-Bild bei Richard Katz, dem 'vergessenen' Exilschriftsteller. In: Blickwechsel: Akten des XI. Lateinamerikanischen Germanistenkongresses, São Paulo, Paraty, Petrópolis 2003, Band 2 / Hrsg. Ulrich J. Beil, Claudia S. Dornbusch, Masa Nomura. São Paulo, Edusp / Monferrer Produções, 2005, 603 -609 .

Dines, Alberto. Prefácio. In: ZwEIG, Stefan. Brasil - um país do futuro. Tradução de Kristina Michahelles. Porto Alegre, L\&PM, 2006, 7-9.

Dines, Alberto. A Morte no Paraíso: A Tragédia de Stefan Zweig. Rio de Janeiro, Nova Fronteira, 1981.

GREGOR-DelLin, Martin. Jeder Satz exotisch. In: Die Zeit, Hamburgo, 29/08/1969, 17. http://www.zeit.de/1969/35/Jeder-Satz-exotisch (03/07/2008).

HuBER, Valburga. “A imagem edênica do Brasil perenizada na literatura dos imigrantes alemães”. In: Blickwechsel: Akten des XI. Lateinamerikanischen Germanistenkongresses, São Paulo, Paraty, Petrópolis 2003, Band 2 / Hrsg. Ulrich J. Beil, Claudia S. Dornbusch, Masa Nomura. São Paulo, Edusp / Monferrer Produções, 2005, 655-659.

KeSTLER, Izabela Maria Furtado. Exílio e Literatura: Escritores de fala alemã durante a época do nazismo. Tradução de Karola Zimber. São Paulo, Editora da Universidade de São Paulo, 2003.

SousA, Celeste H. M Ribeiro de. Retratos do Brasil - Hetero-imagens literárias alemãs. São Paulo, Arte e Cultura, 1996.

ZwEIG, Stefan. Brasil - um país do futuro. Tradução de Kristina Michahelles. Porto Alegre, L\&PM, 2006. 